\title{
Family Communication of University Students on Facebook
}

\author{
Gülçin İpek Emeksiz \\ Anadolu University, Eskişehir, Turkey
}

\begin{abstract}
With the widespread usage of Facebook throughout the world, Facebook has also started to be used in family communication both by adults and young people. Family members and relatives have recently started to take part in this well-known social media platform. Especially, family members and relatives who pursue separate lives in different cities can get together through Facebook and communicate by sharing photos, sending messages or making video calls. Thus, many adults and young people have participated into Facebook to strengthen their family bonds with their relatives and be informed about what their family members are doing in their daily life. The number of studies related with family communication on Facebook is limited in the literature. Especially, the number of studies which focus on how university students maintain family communication with their family members and relatives on Facebook are rather few. Therefore, this research aims to look at how university students keep up family communication on Facebook. For this purpose, a qualitative research was carried out by interviewing 20 students who were enrolled to the Faculty of Communication Sciences at Anadolu University, Turkey.
\end{abstract}

Keywords: family, communication, Facebook, university students

\section{Introduction}

\section{Family Communication and Facebook}

A family is the smallest unit in a society. It takes care of the basic human needs such as affection, protection, nutrition, and education. Communication in families is a significant issue because it plays a significant role in molding the characteristics of individuals in a society. Maintaining healthy communication in families is important for the welfare of society. Therefore, parents should raise their children responsibly by communicating with them well and educate them how to behave properly in society.

How individuals communicate with their family members changes with the developments in technology. Platt, Bourdeaux, and DiTunnariello (2014) draws attention that older generations mainly depend on letters or phone calls, but today's parents are lucky in many aspects as they have many tools in their hands that they can contact with their children. They can send their children a quick e-mail or text message, write on their Facebook timeline, or interact with them through video chat (Platt et al., 2014, p. 76).

Before the rise of the Internet, families mainly relied on telephone and mail services. However, family members could not see each other simultaneously on the phone back then. Moreover, telephone lines could be cut with interference, and the delivery of mail usually took a long time. Thanks to the rise of the Internet and mobile technologies, family members have started to communicate with each other conveniently. Now, an individual can reach his/her family members any time quickly without the barriers of geographic locations as 
the tools of the new era offer options such as video chat and instant messaging applications.

According to the researches of Rudi, Dworkin, Walker, and Doty (2015) who examined family communication patterns of 195 adolescents, how adolescents communicate with their parents has an importance order. The first choice of adolescents is to talk in person with their parents, followed by talking on the phone and text messaging, then e-mailing (Rudi et al., 2015, p. 823).

Platt et al. (2014) made interviews with 21 college students and the results of their research demonstrated that students who were busy when they need to contact with their parents chiefly prefer using text messages or e-mails, but when they have enough time, they prefer to get in touch with their parents through phone calls (Platt et al., 2014, p. 84).

Another research which examined information and communication technology that parents $(N=1,322)$ use to communicate with their children in the U.S.A. showed that over $90 \%$ of parents stated using text message and almost three-quarters stated using social networking sites to communicate with their children (Rudi et al., 2015, p. 85).

The new features of Facebook makes it a favorable tool for family communication. Through Facebook video call and instant messaging, family members can reach each other fast and easily. But, the advantages of using Facebook in family communication is not limited with these. Parents primarily use Facebook in order to keep an eye on what their children is doing.

Young people announce where they are and with whom they are through the pictures they share on Facebook. This way, parents, who are friends with their children on Facebook, can track the daily developments in the lives of their children. This way, they not only satisfy their curiosity, but also know whether their children spend time in safe environments or not.

In fact, one third of people using social networking sites uses it for surveillance and they watch closely what their friends, family members and celebrities are doing (Strategic Direction, 2015, p. 6). According to a research conducted in England, seven in ten parents use social networking sites such as Facebook for family communication and 62 percent of them admitted that they check what their children like on Facebook (London, 2013). This way, parents can know on what topics and issues their children have interest.

However, children try to stay away from this surveillance and try to hide their private life from their parents by declining their parents' friendship requests or by applying privacy settings. West (2009) carried out a qualitative research with 16 university students to find out whether students add their parents as friends on Facebook and the results of her research showed that students mostly do not add their parents as friends on Facebook (West, 2009, p. 615).

As a matter of fact, declining the friendship request of parents, blocking parents or making privacy management towards parents on Facebook is a tough issue as it will most highly create a potential source of conflict within families (Miller, Danielson, Parcell, Nicolini, \& Boucher, 2016, p. 4). Nevertheless, the reasons behind this attitude of young students are related with the fact that their parents sometimes embarrass them in front of their friends by talking about their arguments and students do not want their parents to see their pictures when they are drunk or smoking (West, 2009, pp. 620-621).

Another interesting point is that young students do not display their Facebook profile as the way it is to their parents even when they accept their parents' friendship offer on Facebook. According to the researches of Ball, Wanzer, and Servoss (2013), 25\% young students who accept their parents' friendship requests tend to make changes on their Facebook profile immediately (Ball et al., 2013, p. 623). 
Nonetheless, young students do not only apply privacy settings to their parents on Facebook. Some students do not prefer revealing too much information about their families to their friends on Facebook, as well. According to Platt et al.'s (2014) researches, some of the students abstain from discussing private information related with their families on Facebook in order to preserve their family's privacy; instead they use Facebook messenger for family communication in order to keep the conversation more personal rather than public (Platt et al., 2014, p. 91).

On the other hand, maintaining family communication on Facebook has many benefits since distant relatives connect with each other even if they haven't seen each other for a long time and family relationships are improved despite living far from each other. Most of the researches point out that Facebook generally impacts family relationships in a positive way as it makes connections stronger among family members despite physical distances (Miller et al., 2016, p. 7).

\section{Purpose of the Research}

The number of researches that has been conducted concerning the role of Facebook in family communication are limited in the literature. This research examined the advantages of using Facebook for family communication and it also looked at whether university students take any precautions on Facebook in order not to give a damage to their family communication. In addition, this research compared the efficiency of other multimedia tools used in family communication with Facebook from the perspective of university students.

\section{Method}

With these goals in mind, 20 university students who currently study in two different departments of the Faculty of Communications Sciences at Anadolu University in Turkey were interviewed with the semi-structured interview technique on December 20, 2016. The interview technique is beneficial in the sense that the low return ratio problem encountered in surveys can be removed, additional questions can be asked to learn the situation further and the body language of the participants can be analyzed (Şimşek, 2015, p. 178). Before the interviews, the students were informed that participation into the research is voluntary. The students were interviewed with open-ended questions in a meeting room one by one and the interviews were voice recorded by the researcher. Each of the interview took approximately 15 minutes. Afterwards, the researcher transcribed the interviews and applied descriptive analysis by creating thematic codes.

\section{Results}

\section{The Number of Years that Students Have Been Using Facebook}

In general, the university students have been using Facebook approximately for 7 to 10 years. Most of them opened an account when they were going to secondary school.

\section{The Time Span that Students Spend on Facebook}

The time span that university students spend on Facebook changes between 1 and 5 hours a day.

\section{The Frequency of Using Facebook While Communicating With Family Members and Relatives}

One of the great advantage of Facebook in family communication is its video call feature. Some of the university students said that they use Facebook primarily for video call to communicate with their family members and relatives. For instance, one of the student communicates with his relatives living in abroad two or 
three times a week for half an hour through the video call feature that Facebook provides. Another university student who uses Facebook video call to talk with his family members said that he talks with his family members approximately 1.5 and 2 hours a day, which shows that he spends a considerable amount of time on Facebook for family communication.

However, most of the university students said that they use Facebook superficially while communicating with their family members and relatives. This is an interesting point. According to the statements of students, they do not often use Facebook for family communication. They said that they only like their family members' and relatives' pictures on Facebook and they look at what their family members and relatives share on Facebook.

\section{The Advantages that Facebook Provides for Family Communication}

Most of the university students are in the opinion that the most significant advantage of using Facebook in family communication is that Facebook is a fast way of communication. Some of the university students said that they cannot reach their family members via cell phone all the time because there are times when their family members cannot be convenient. However, by sending a message from Facebook messenger students can reach their family members, even if they are in a meeting.

From the perspective of parents in general, the advantage of using Facebook for family communication is that they can know what their children is doing. However, some of the university students are not content from the fact that their parents can reach them any time they want through Facebook video call. One of them said that her parents might not like the places they hang out. Therefore, she cannot always accept her family members' video calls.

Duygu, Female, 24: "Since Facebook is quick and fast, it is a blessing for my mother. When she cannot reach me, she directly calls me from video call. Maybe, this is a disadvantage for me, but it is a great advantage for my mother. She can know where I am and what I am doing easily through Facebook video call. I cannot open video call when I am outside because little problems can emerge. I usually open it, when I am at home".

Thanks to Facebook, young students can know what is happening in the daily life of their family members and their relatives. As students are having a university life in Eskisehir, which is a northwestern city in Turkey, most of them are distant from their hometowns. Thanks to Facebook, university students can follow where their family members have gone in the last few days. Also, they can meet with their relatives whom they haven't seen for a long time through Facebook. Therefore, Facebook makes long distances short for them. Facebook is also a great place for catching up with relatives' lives.

Kübra, Female, 22: Since my mother lives outside of Eskisehir. I cannot always reach her by cell phone, then I write her from Facebook. I can make video call. I can follow my relatives whom I haven't seen for a long time from Facebook and see what they are doing. Sometimes, when I share a picture on Facebook, they make a comment and this way we can get in touch.

Moreover, when students are left without credits on their cell phones, they can easily communicate with their family members through Facebook. Since Facebook is a free communication tool, it is a great advantage for students whose budgets are limited.

\section{The Content that Students Share With Their Family Members and Relatives on Facebook}

Most of the students said that their communication with their family members and relatives on Facebook is related with daily life. These students said that they keep their communication simple and short on Facebook. 
They said that they ask daily questions such as "how are you?", "what are you doing?", and "how was your day?" to their family members through the messenger of Facebook.

Furthermore, most of the students said that they share posts with their family members on Facebook on special days. Students celebrate birthdays, weddings, and mother's and father's days on Facebook. They share their memories and family photos with each other.

In general, students said that they share content on Facebook to fulfill their longings with their family members. By sending videos and pictures of themselves to their family members and relatives, young people fulfill their longings as they live in different cities with their family members and relatives.

Moreover, some of the students said that they abstain from sharing political content with their family members and relatives on Facebook. These students do not want to involve in political debates with their family members and relatives on Facebook.

In addition, students inform their family members about how university life is going in Eskisehir and what their further projects are through Facebook.

\section{The Content that Family Members and Relatives Share With the Students on Facebook}

Family members and relatives of the students also share with them their daily plans, what's happening in their hometowns and their future plans. Family members and relatives also let students know about approaching events such as weddings and tell students to come home in special days. In addition, family members share photos on special days such as birthdays and graduation ceremonies. They also share news and funny videos with students.

However, some of the students are not content from the fact that their family members and relatives comment on every single picture they share on Facebook. They do not want their comments to be seen in front of their other Facebook friends.

Ezgi, Female, 22: My family members and relatives tag me into pictures and they constantly make comments on my pictures. This disrupts me.

\section{Precautions that Students Take for not Giving Harm to Their Family Communication on Facebook}

Some of the students underlined that they abstain from involving in political debates on Facebook in order not to bother their family members. Another precaution that students take is to apply privacy settings to their family members and relatives in order not to give damage to their relationship with their posts. When students do not want their family members to see their posts, they apply privacy settings to them. Some of the students said that they do not share their photos with alcohol on Facebook because their families are conservative.

Kadir, Male, 23: I try to stay away from politics on Facebook. If my family members or relatives share a political post, I ignore it. This way, I do not give damage to the bond between us.

Hüseyin, Male, 25: I never share a political post on Facebook. My family is conservative. Also, when I am outside with my friends, I do not put pictures with alcohol.

Also, some of the students do not tag their pictures with their boyfriends or girlfriends on Facebook. They think that their family members or relatives can react strictly if they know that they date with somebody. These students implied that they do not want to reveal their private life in front of their family members and relatives. Thus, they hide their pictures by applying privacy settings on Facebook.

Merve, Female, 24: Of course, there are some precautions that I take. I do not tag my photos with my boyfriend on Facebook because problems can emerge. Especially, my uncle is strict about these issues. 
Therefore, I hide my photos from him. For instance, last summer I went on a vacation with my boyfriend, but I hided my photos on Facebook. Also, most of my girlfriends who have boyfriends either hide their photos on Facebook or they do not add their family members as friends on Facebook.

Furthermore, some of the students said that they do not open an additional Facebook account in which they can only be friends with their friends from university. They said that they do not share everything related to their lives on Facebook where their family members and relatives are. They share some of the things related to their lives on other social media platforms where their family members and relatives are absent.

On the other hand, some of the students said that they used to apply privacy settings to their family members and relatives when they were young, but they don't do it anymore. These students said that they used to hide some of their posts from their family members because their family member always did not know where they were going. There were times that students hided their posts from their family members because they didn't want to show their circle of friends. These students think that their families would not approve their circle of friends back then.

Some of the students said that when their friends tag them into pictures when they go out, they do not allow these pictures to be seen in their Facebook timeline. This way, their parents and relatives don't know about where they have gone with their friends. From their statements, it looks like university students don't want to reveal their private life in front of their family members.

\section{Positive Experiences of Students While Using Facebook in Family Communication}

Most of the positive experiences of students on Facebook are related with getting together with their family members and relatives. Some of the students said that they usually gather with their family members and relatives under a family photo shared on Facebook, which helps them to strengthen their family bond. By sharing their thoughts under the family pictures, the students and their families have a pleasurable time. Sometimes, they look at old photos, make nostalgia and talk about the past good days.

\section{Negative Experiences that Was Encountered While Using Facebook in Family Communication}

According to university students, little problems can emerge between students and family members when their family members learn things related to their private life from Facebook. These problems can be related with boyfriend and girlfriend issues. Also, students are sometimes criticized or misinterpreted by their family members and relatives due to pictures reflecting their circle of friends. Therefore, students have a tendency to apply privacy settings to their family members and relatives.

Tunahan, Male, 22: I drew the reaction of my family members and relatives because of the pictures I shared related to my circle of friends on Facebook. I was misunderstood by my family members and relatives because of my circle of friends in my university. I was criticized by them. Since then, I have been hiding some of my posts from my family members and relatives on Facebook.

Furthermore, university students do not want their family members and relatives to tag them into pictures without letting them know because they want to protect their self-image.

Ezgi, Female, 22: Sometimes my family members or relatives tag me in pictures in which I don't look good. Then, I'm embarrassed in front of my friends on Facebook.

\section{Pros and Cons of Using Facebook in Family Communication Compared to Face to Face Communication}

Most of the university students think that face to face communication is more effective than Facebook communication because their body language, their face expressions and their voice help them convey their 
messages healthily to their family members. Also, they said that they can see the reaction of their family members when they talk with them face to face. They said that on Facebook they try to communicate with the help of emojis, which are not adequate to support their thoughts. Another handicap of Facebook communication is that Internet connection must be good all the time, otherwise it is not possible to communicate smoothly. Furthermore, students mentioned that when they communicate with their family members face to face, their family members tend to explain private things more often. Thus, students indicated that they can create a more close relationship with their family members when they communicate face to face.

On the other hand, students do not have a chance to see their family members and relatives physically whenever they want as they live in different cities. Therefore, they cannot use face to face communication all the time. At that point, Facebook makes their lives easier. They can connect to their family members and relatives through video call and fulfill their longings. In the meantime, students pointed out that since the number of Facebook users have dramatically increased in Turkey in the last few years, nearly all of their family members and relatives have a Facebook account. Thus, they can even communicate with their relatives whom they haven't seen for years.

\section{Pros and Cons of Using Facebook in Family Communication Compared to Cell Phone}

Most of the students are in the opinion that Facebook is more effective than telephone in reaching more family members or relatives because telephone conversations usually take place between two people and when the cell phone is out battery, it is hard to reach them. Nevertheless, students emphasized that they can reach Facebook from different devices such as smart phones, laptops, ipads and computers. They also said that Facebook's video call feature is more effective than telephone as it is both visual and audial.

\section{Pros and Cons of Using Facebook in Family Communication Compared to E-mail}

Most of the students said that they do not use e-mail in family communication at all. They underlined that e-mail is old fashioned and they use e-mail only in formal tasks. Moreover, they said that as their family members are from an older generation, they do not know how to use e-mail. Generation gap plays an important role in the choice of the communication tool that parents prefer to communicate with their children. On the other hand, most of the students' family members opened Facebook out of curiosity. This is an interesting finding which might show that Facebook usage may be more widespread among older people than e-mail usage in Turkey. Thus, it looks like e-mail is not a favored choice for family communication of students.

Kadir, Male, 23: I think Facebook has many advantages compared to e-mail. My mother and father do not use e-mail because they are from an older generation. However, they opened a Facebook account out of curiosity.

\section{Why WhatsApp is One Step Ahead in Family Communication than Facebook, According to Students}

The reason why most of the students do not prefer Facebook for family communication is that students and their families use the online messenger application downloaded on smartphones named WhatsApp more frequently to communicate through text or audio messages. According to some of the students, Facebook is a communication tool which is used in emergency situations. When students cannot reach their family members through their smartphone or the online messenger application named WhatsApp, they prefer using Facebook for family communication. They said that in such circumstances their family members immediately start video call from Facebook and try to reach the students.

Duygu, Female, 24: Since WhatsApp provides video call, I use Facebook for family communication less. For instance, if a problem arouses on WhatsApp, my mother is directed to Facebook and starts video call from 
Facebook. My father writes in every two week from Facebook. We generally use WhatsApp for family communication.

Yiğit, Male, 24: I think WhatsApp is in the front of Facebook in family communication. The usage of WhatsApp is widespread. When a message arrives to me from Facebook messenger, I don't usually look at it. However, I frequently check my messages in WhatsApp.

In addition, most of the students said that WhatsApp has some useful features that make communication easier and simple than Facebook. One of them is that people who use WhatsApp can see whether the person they send a message have read their message or not. Furthermore, one has to wait for the other person to be active on Facebook to communicate at the same time, but this is not the case on WhatsApp. When one sends a message on WhatsApp, the message is directly seen on the screen of the receiver's smart phone. Since it is a practical web-based tool, WhatsApp is commonly used among family members and it is the first choice for family communication compared to Facebook. In addition, creating groups with family members on WhatsApp facilitates every family member to see the message sent by other family members.

Kerem, Male, 21: WhatsApp is one step ahead in family communication than Facebook. You are not always active on Facebook and you wait for the person you communicate with to be active, as well. This is not the case in WhatsApp. When the message is created, it is directly seen by the receiver. WhatsApp facilitates an easier way of communication.

\section{Applying Privacy Settings to Family Members and Relatives on Facebook}

Most of the students apply privacy settings to their family members because they think that their relatives do not know how to use Facebook appropriately for conversations. Some of the students said that their relatives disregard the fact that general posts on Facebook are open to everyone's view and they talk as if they were making private conversations.

Aytunga, Female, 23: I applied private settings to my relatives because when they write me something, I have to respond. However, they start conversations on Facebook as if it was a private space. They start talking about what has happened the other day. They should write from the messenger, instead. When I warn them, they don't understand.

Yusuf, Male, 22: My family members sometimes talk private things in front of everybody's view on Facebook, which is an unconscious behavior.

Some of the students said that Facebook has turned into a place where adults spend time more. Therefore, students said that they prefer spending time in other social media platforms which addresses to younger people. They said that they do not use Facebook for family communication because they do not want to apply privacy settings to their family members and relatives.

Aylin, Female, 23: Facebook addresses to people who are middle aged and above. In the last two years, there is almost nobody who hasn't got a Facebook account. Therefore, I don't prefer communicating with my family members and relatives through Facebook. When I decline their friendship offer, they have an attitude toward me. I don't apply privacy settings, either. I prefer using social media channels such as Twitter, Instagram and Tumblr. As these platforms addresses to young people, my family members and relatives are not there.

Some of the students said that they applied privacy settings to their family members because when their family members are on Facebook, they cannot express their thoughts openly. When they express their thoughts on Facebook freely, they are criticized by their family members afterwards. 
Kerem, Male, 21: I applied privacy settings to my family members because I cannot freely express my thoughts on Facebook when they are there. I sometimes make a comment on Facebook, but when I come home, my family members ask me a lot of questions. Therefore, I have limited my posts and have applied privacy settings to my family members.

Some of the students apply privacy settings on Facebook in order to preserve their private life about their romantic relationships. The statements of the students show that they do not want to disclose too much information about their romantic relationships to their parents because they don't want to concern them.

Duygu, Female, 24: I use privacy settings on Facebook. I limit my posts to my father. He knows my boyfriend. However, when he sees my pictures with my boyfriend, he becomes jealous since I am his only daughter. I limit my posts because I don't want to upset him.

One of the students think that he no longer need to apply privacy setting towards his family members. This student is in the opinion that if he use Facebook in a proper way, he doesn't need to hide anything from his family members.

Salih, Male, 24: I no longer apply privacy settings to my family members. I used to think that when my family members saw my Facebook posts there would be negative reflections. However, I use Facebook more carefully now and I don't hide anything from my family members because they are my family.

\section{Discussion}

Facebook is still the most popular social media platform in the world that people use to connect with their friends, learn about daily happenings around them, and express their thoughts and feelings. It is also used by young people and adults for family communication. According to the statements of the university students, who were interviewed some of the advantages that Facebook provides for family communication is that it is a fast and free social media tool that helps them to connect with their family members and relatives, and learn what is going on in the lives of them.

The most common activities that young students do with their family members on Facebook are to celebrate special days, comment under old pictures, and talk about daily events and future plans. Most of the students are in the opinion that Facebook making distances short helps students to fulfill their longings with their family members and relatives. However, in order not to give damage to their family relationships, most of the students take some precautions and apply privacy settings on Facebook towards their family members and relatives. The students think that if their parents learn about their romantic relationships, circle of friends, or the places that they hang out, little problems can emerge.

The students complain from the issue that their family members and relatives misinterpret their circle of friends when they see pictures on Facebook. Drawing attention that their family members and relatives are conservative, the students said that they hide their pictures with alcohol or the vacations that they went with their boyfriends. The students also abstain from involving in political debates or expressing their point of view with their family members and relatives on Facebook so as not to give a damage to their relationships. Nevertheless, some of the students mentioned that when they apply privacy settings towards their family members and relatives, their family members and relatives strike an attitude.

Most of the students said that they use Facebook superficially in family communication. They said that their families do not prefer talking about private things on Facebook, instead they prefer talking face to face. The students said that they mainly use Facebook in emergency situations to talk with their parents and family 
members. Most of the students think that WhatsApp is ahead in family communication than Facebook since it is a mobile application used in smartphones, which is more practical and handier. Therefore, the most noteworthy result of this research is that WhatsApp is more frequently used by university students for family communication than Facebook. Therefore, it looks like WhatsApp makes a substantial change in the order of importance of the tools used in family communication in Turkey.

\section{Limitation}

Since this is a qualitative study, the findings of the research cannot be generalized. In addition, this research only reflects the point of view of university students related with family communication on Facebook. In the future, another qualitative research can be made with parents and their perspectives can be compared with students.

\section{References}

Ball, H., Wanzer, M. B., \& Servoss, T. J. (2013). Parent-child communication on Facebook: Family communication patterns and young adults' decisions to friend parents. Communication Quarterly, 61(5), 615-629.

London, B. (2013). Family time goes digital: Seven in ten parents turn to social networks to communicate with their children as Twitter and Facebook replace kitchen table chats. Retrieved from http://www.dailymail.co.uk/femail/article-2350572/Seven-parents-turn-social-networks-communicate-children-Twitter-Face book-replace-family-chats.html

Miller, J. H., Danielson, C., Parcell, E. S., Nicolini, K., \& Boucher, T. (2016). Blurred Lines: Privacy management, family relationships, and Facebook. Iowa Journal of Communication, 48(1), 4-22.

Platt, C. A., Bourdeaux, R., \& DiTunnariello, N. (2014). Should I Text or Should I Call? How college students navigate mediated connections with family. Communication and Information Technologies Annual, 8, 75-101.

Rudi, J., Dworkin, J., Walker, S., \& Doty, J. (2015). Parents' use of information and communications technologies for family communication: Differences by age of children. Information, Communication and Society, 18(1), 78-93.

Şimşek, A. (2015). İletişimAraştırmalarındaParadigmaDeğişimi (Paradigm shift in communication researches). In B. Yıldırım (Ed.), IletişimAraştırmalarındaYöntemler (Methods in communication researches) (155-196). Konya: Literatürk.

Strategic Direction. (2015). So why do people use Facebook and Twitter? Uses and gratifications of social media use. Strategic Direction, 31(6), 4-6.

West, A. (2009). Students' Facebook “friends": Public and private spheres. Journal of Youth Studies, 12(6), 615-627. 